\title{
Prácticas discursivas acerca de la Segunda Guerra Mundial en Japón y sus corolarios neonacionalistas
}

\section{Discursive practices about World War II in Japan and its neo-nationalist corollaries}

\author{
ESTEBAN CÓRDOBA ARROYO \\ Universidad de Kyushu | Universidad de Kitakyushu, \\ Kyushu, Japón \\ e-cordoba@kitakyu-u.ac.jp
}

Resumen: La reconstrucción selectiva de la Segunda Guerra Mundial por parte de ultranacionalistas en Japón ha avivado sentimientos antijaponeses y debilitado las relaciones internacionales en el Este de Asia. Sin embargo, el discurso ultranacionalista con el que se suele asociar a todo el colectivo japonés es solo uno de muchos que luchan por reconocimiento en la esfera pública japonesa. ¿Cuáles de estos discursos coexisten y compiten en la sociedad japonesa y qué implican para el neonacionalismo en el Este de Asia? Mediante el uso de fuentes primarias, este artículo investiga patrones de conmemoración de la Segunda Guerra Mundial ampliamente difundidos en la sociedad y la cultura de Japón desde el final de la guerra hasta el presente. Esto, con el objetivo de crear un marco sistemático que muestre sus principales presupuestos y consecuencias.

Palabras clave: Memoria colectiva, Segunda Guerra Mundial, Problema histórico en el Este de Asia, Neonacionalismo, Japón. 
Abstract: The selective reconstruction of World War II by ultranationalists in Japan has fueled anti-Japanese sentiments and weakened the international relations in East Asia. Nevertheless, the ultra-nationalist discourse with which the entire Japanese collective is often associated is just one of many positions struggling for recognition in the Japanese public sphere. Which of these "discourses" have become coexist and compete in Japanese society and what do they imply for East Asian neo-nationalism? Using primary sources, this paper examines the patterns of commemoration of World War II that have been widespread in Japanese society and culture from the end of the war to the present. This with the aim of creating a systematic framework that reveals their main assumptions and consequences.

Keywords: Collective memory, World War II, History problem in East Asia, Neo-nationalism, Japan.

Citar como: Córdoba-Arroyo, E. (2022). Prácticas discursivas acerca de la Segunda Guerra Mundial en Japón y sus corolarios neonacionalistas. Revista Internacional de Estudios Asiáticos, 1(1), 184-225.

Fecha de recepción: 21-09-2021 | Fecha de aceptación: 09-11-2021 


\section{Introducción}

Así como dos guerras mundiales aplastaron las expectativas de aquellos teóricos sociales del siglo XIX que creían que el nacionalismo declinaría en favor del internacionalismo, del mismo modo, el renacimiento de los nacionalismos étnicos desde la década de 1990 y el auge del populismo xenófobo en el siglo XXI han acabado con las esperanzas de quienes pensaban que el cosmopolitismo sería el resultado del proceso de globalización. En el Este de Asia, el nacionalismo y la xenofobia han sido constantemente avivados por diferencias en la reconstrucción de la memoria colectiva de la Segunda Guerra Mundial, principalmente desde el decenio de 1990, cuando estas diferencias escalaron hasta convertirse en el núcleo de los problemas internacionales en la región. ${ }^{1}$ Durante el siglo XXI la situación no ha dejado de ser

1 A principios de la década de 1980 , se produjeron cambios fundamentales en las formas sociales de recordar la Segunda Guerra Mundial en Japón, un fenómeno conocido como el "problema histórico" (rekishi mondai). Entre esos eventos se encuentran: a) la primera controversia sobre los libros de texto de historia y la "Declaración de Miyazawa" en 1982; b) el problema del Santuario de Yasukuni (1985) -que desencadenó la decisión del Primer Ministro Yasuhiro Nakasone de abstenerse de realizar más visitas oficiales al Santuario-; c) un aumento en el número y tono de las disculpas oficiales dadas por políticos japoneses; d) la publicación de varias confesiones de veteranos japoneses acerca de sus crímenes en Asia y e) la muerte del emperador Hirohito (1989), que fue seguida por una avalancha de debates sobre la responsabilidad del monarca durante la guerra. Tales eventos, durante la década de 1980, contribuyeron tanto al cambio sociopolítico progresista conocido como el "giro mnemónico de la década de 1990", como al contragolpe ultranacionalista desde 1995 hasta el presente. Sobre este tema véanse: Kazuya Fukuoka, "Memory and Others. Japan's mnemoic turn in the 1990s", en Routledge Handbook of Memory and Reconciliation in East Asia, ed. por Mikyoung Kim. (Abingdon: Routledge, 2015), 63-78; y Ryuji Hattori, Understanding History in Asia What Diplomatic Documents Reveal (Tokio: Japan Publishing Industry Foundation for Culture, 2019). En la literatura en castellano, las raíces de estos problemas son exploradas en Ferran De Vargas, Izquierda y Revolución: Una historia politica del Japón de posguerra (Barcelona, Editorial Bellaterra, 2020). Nota: 
tensa, pues casi todos los conflictos -limítrofes, comerciales, etc.- acaban fundiéndose con el siempre latente y esquivo "problema histórico".

En este contexto, el infatigable activismo de grupos ultranacionalistas en Japón invita la indignación -y el nacionalismo- de los países que fueron víctimas de la agresión japonesa. Estos grupos extremistas reconstruyen de manera selectiva la memoria de la guerra, justifican la participación japonesa, minimizan o abiertamente niegan los crímenes cometidos por el Ejército Imperial Japonés, mientras destacan las hazañas y el coraje de sus soldados. Sin embargo, aunque la membresía y popularidad de estos grupos son mínimas, sus críticos suelen culpar a los japoneses in totto, como un pueblo impenitente que carece de conciencia histórica. ${ }^{2}$

No obstante, el discurso ultranacionalista es solo uno de tantos que han estado luchando por reconocimiento en la esfera pública japonesa. Distintos grupos sociales han desafiado, respaldado o ignorado la posición nacionalista en un proceso siempre fluctuante. Es posible pensar que ha habido tantas maneras de recordar como seres humanos. Sin embargo, con el paso del tiempo la memoria colectiva de las sociedades, a pesar de ser originalmente rica y caleidoscópica, tiende a la homogenización y simplificación, y se convierte en lo que algunos autores han llamado "discursos", "patrones narrativos” o "esquemas mentales" para

Los nombres japoneses se escribieron antes del apellido tanto en las referencias como en el cuerpo del trabajo por motivos de coherencia con el Manual de Citación de Estilo Chicago de Chicago. Las referencias de fuentes en japonés siguieron las convenciones de estilo indicadas en Michael Radich, A Student's Guide Writing in East Asian Studies (Cambridge: Harvard University Press, 2007). La romanización del japonés utiliza el sistema Hepburn Revisado con uso de macrón. 2 Una crítica al ultranacionalismo japonés acompañada por un reconocimiento a aquellos académicos japoneses que han luchado por combatirlo puede consultarse en Laura E. Hein y Mark Selden, Censoring History: Perspectives on Nationalism and War in the Twentieth Century: Asia and the Pacific (New York: M. E. Sharpe, 2000), 46-47. 
abordar el pasado. ${ }^{3}$ ¿Cuáles han sido estos discursos que han llegado a consolidarse en la sociedad japonesa y qué implican con respecto al neonacionalismo?

Varios académicos ya han investigado estas tendencias discursivas a propósito de esta guerra. ${ }^{4}$ Sin embargo, hay un exceso de conceptos utilizados para referirse a la misma cuestión, mientras que hay diferencias significativas ignoradas bajo el mismo término. Además, no ha habido un intento de sistematización de tales discursos. Por este motivo, este trabajo intenta

3 En este trabajo el concepto "discurso" es definido como "un cuerpo de uso del lenguaje unificado por suposiciones comunes" o "estructuras de pensamiento" que no solo dan forma al recuerdo colectivo, sino que también "enmarcan la discusión en cuanto a lo que puede ser dicho o pensado", véase: Abercrombi et al., The Penguin Dictionary of Sociology, 111-112. La palabra discurso debe ser entendida en este sentido y no implica necesariamente la carga conceptual de las diferentes teorías del discurso. La idea de que la memoria colectiva se simplifica hasta convertirse en una suerte de esquema mental (mental schemata), usado por los individuos para reconstruir el pasado, se encuentra en Jeffrey K. Olick. "From Collective Memory to the Sociology of Mnemonic Practices and Products", en $A$ Companion to Cultural Memory Studies, ed. por Astrid Erll y Ansgar Nünning (Berlin/New York: Gruyter, 2010), 151-161. El término "patrones narrativos” (narrative patterns) es usado en un sentido similar en Akiko Hashimoto, The Long Defeat: Cultural Trauma, Memory, and Identity in Japan (New York: Oxford University Press, 2015).

4 Akiko Hashimoto, The Long Defeat, divide la memoria colectiva de la II Guerra Mundial en la sociedad japonesa en tres narrativas: nacionalismo, pacifismo y reconciliación. Sobre este tema véanse también: John W. Dower, Ways of Forgetting, Ways of Remembering Japan in the Modern World (New York: The New Press, 2012) y Kiyoteru Tsutsui, “The Trajectory of Perpetrators' Trauma: Mnemonic Politics around Asia-Pacific War in Japan”, Social Forces 87, no. 3 (2009): 1389-1422. En japonés: Yutaka Yoshida 吉田裕, Nihonjin no sensōkan sengōshi no naka no hen'yo-日本人の戦争観 戦後史のなかの変容 [Visión japonesa de la guerra: transformación en la historia de la posguerra] (Tokio: Iwanami Gendai Bunkō, 2005). 
contribuir a llenar ese vacío. La siguiente sección explica el método utilizado para analizar esos discursos, mientras que en la tercera y cuarta se presenta la sistematización del autor. En la sección final, se analizan los presupuestos de cada discurso y sus consecuencias en relación con el neonacionalismo.

\section{Método}

Durante tres años se llevó a cabo una revisión sustantiva de las fuentes primarias relacionadas con la construcción sociocultural de la memoria de la Segunda Guerra Mundial en Japón, estas incluían autobiografías de exmilitares de la Armada y el Ejército Imperial Japonés, discursos de políticos de alto rango, editoriales de periódicos, crónicas periodísticas, novelas, poemas, estudios filosóficos y productos de la industria cultural como cómics, animaciones y películas. ${ }^{5}$ Se intentó llevar a cabo una arqueología -en el sentido foucaultiano- de las capas discursivas que, a través de una pluralidad de medios y actores, se han ido acumulando desde finales de la década de 1940 hasta ya entrados los años setenta. Una vez convertidos en "discursos", las diferentes reconstrucciones de la memoria de la guerra han luchado por el reconocimiento en la esfera pública japonesa, particularmente desde el decenio de 1980 hasta alcanzar su momento más álgido en los años noventa. Un primer análisis de estas fuentes reveló que casi todos los materiales se podían categorizar como: a) el intento de explicar los orígenes de la Segunda Guerra Mundial en Asia, y b) el intento de representar -y evaluar-a las personas que vivieron durante ese periodo. Posteriormente, se realizó una investigación en forma

5 La selección de un corpus considerable de análisis es inherentemente subjetiva. Este trabajo buscó reducir el sesgo de la subjetividad, pero no pretende ser exhaustivo. La selección de los datos se decidió consultando a un equipo de sociólogos y expertos en medios japoneses. Su sugerencia fue utilizar dos criterios: niveles de circulación y críticas internas. Solamente fueron seleccionados aquellos materiales que gozaron de altos niveles de circulación (éxitos de ventas, películas de culto, etc.) o que recibieron amplia divulgación mediática. En la siguiente sección se enumeran algunos de los materiales consultados. 
de análisis de contenido y análisis narrativo. ${ }^{6}$ Esta segunda fase sugirió la existencia de subcategorías con relación a la explicación de la guerra y la representación de quienes participaron en ella (véanse las Tablas 1 y 2). Finalmente, una última revisión de los materiales reveló diferencias significativas ignoradas en la literatura secundaria, por ejemplo, la existencia de diversos tipos de "conciencia de víctima", "conciencia de agresor" o "conciencia heroica".

\section{¿Por qué Japón entró en la guerra? Los discursos acerca de los orígenes de la Segunda Guerra Mundial en Asia}

El análisis de las fuentes primarias mostró que, si bien la mayoría de los textos evitaban tratar el tema del involucramiento de Japón en la Segunda Guerra Mundial, aquellos que lo hacían solían adherirse a narrativas bastante articuladas. ${ }^{7}$ Por supuesto, durante toda la posguerra se han desa-

6 El método de análisis de contenido y análisis narrativo se basó en las pautas proporcionadas por Catherine K. Riessman, Narrative analysis (California: SAGE Publishings, 1993) y el proceso de codificación del texto siguió las propuestas de Ian Hodder, "The Interpretation of Documents and Material Culture" en Handbook of Qualitative Research, ed. por Norman K. Denzin e Yvonna S. Lincolnn (California: Sage, 1994), 393-402. Se intentó, en la medida de lo posible, prestar atención a los niveles textuales, contextuales y sociológicos sugeridos por Jorge Ruiz, "Sociological Discourse Analysis: Methods and Logic", Forum Qualitative Sozialforschung X, no. 2 (2009), https://doi.org/10.17169/fqs-10.2.1298.

7 Por razones de espacio es imposible citar todas las fuentes primarias consultadas. Algunos ejemplos son la voluminosa Daitōasensō zenshi $i$ 大東亜戦争全史 [Historia completa de la Gran Guerra por Asia Oriental] (1953) de Takushiro Hattori, quien fuese secretario personal del Primer Ministro Hideki Tōjō; las memorias escritas desde la prisión de Sugamo que se convirtieron en éxitos de ventas como Sugamo no byōjō - senpan gokuchū hiwa 巣鴨の表情- 戦犯獄中秘話 (1949) de Ryochi Sasagawa; la revista de los veteranos de la Armada Imperial de Japón Nibon rikukaigun no sōkessan zasshi 日本陸海軍の総決算 雑誌 entre 1955 y 1956; los éxitos de ventas del periodista Masanori Ito, quien tuvo trato directo con 
rrollado interpretaciones plurales acerca del origen del conflicto, pero con el paso del tiempo, aquella pluralidad se ha reducido y simplificado. Por ejemplo, la lectura de las autobiografías de exmilitares de la Armada y el Ejército Imperial Japonés publicadas en los primeros años de la posguerra muestra sorprendente similitud con las posiciones de los ultranacionalistas del presente. Asimismo, las explicaciones del conflicto provistas por escritores marxistas durante aquellos años siguen siendo reproducidas por la izquierda actual, casi sin cambios. Entre ambas posiciones, la más difundida en los medios de comunicación es aquella establecida por las tropas de ocupación estadounidenses y los gabinetes conservadores japoneses y que deposita la carga de la culpa únicamente en la cúpula militar japonesa de aquel entonces. En esta sección se explicarán los elementos centrales de estas tres narrativas predominantes: 1 ) responsabilidad de los líderes (shidōsha sekinin shikan), 2) justificación (daitōasensō kōtei-ron), y 3) el imperialismo japonés (nibon no teikoku shugi). ${ }^{8}$

los altos generales del Ejército japonés como Rengō kantai no saigo: Taiheibiromi senshi 連合艦隊の最後: 太平洋海戦史 [El final de la Armada Imperial de Japón: La Guerra del Pacífico] (1956) y Rengō kantai no eikö連合艦隊の栄光 [La gloria de la flota combinada] (1962). También se consultaron las obras de autores marxistas como Tetsugaku nōto哲学ノート [Notas filosóficas] (1941) de Kiyoshi Miki,Jijoden自叙伝 [Autobiografía] de Hajime Kawakami y la colección de cartas de Hotsumi Ozaki, publicadas póstumamente en 1946 como Aijō wa furu boshi nogotoku 愛情はふる星のごとく [El amor es como una lluvia de estrellas]. 8 En la literatura académica en japonés estos conceptos se utilizan como términos técnicos (shidōsha sekinin shikan指導者責任史観; daitōasensō kōtei-ron大東亜 戦争肯定論 y nihon no teikoku shugi日本の帝国主義). “Justificación” no es una traducción literal del término "daitōasensō kōtei-ron" que significa "teoría afirmativa de la Gran Guerra por Asia Oriental” o "La Gran Guerra fue justa". En este trabajo el concepto "justificación” es usado heurísticamente para facilitar la compresión. Es importante aclarar que estas categorías ya han sido exploradas en la literatura académica en inglés y japonés. El autor se ha limitado a corroborar su extensión y profundidad en las fuentes primarias. La contribución del artículo se encuentra en el desarrollo de las subcategorías de representación explicadas en la siguiente sección. 
La narrativa llamada "responsabilidad de los líderes" (shidosha sekinin shikan) enfatiza que la responsabilidad de iniciar y, sobre todo, de perder la guerra recae únicamente en los líderes militares japoneses de aquel entonces. Este discurso fue construido por políticos japoneses conservadores y por los miembros de las oficinas del Cuartel General del Comandante Supremo de las potencias Aliadas (GHQ por sus siglas en inglés). Este discurso afirma que los japoneses fueron engañados (damasareta) por un pequeño grupo de militaristas que se aventuraron en políticas beligerantes que terminaron en desastre.' Se traza una línea no solo entre los líderes y los ciudadanos, sino también entre el emperador Hirohito -quien no era más que otra persona engañada- y los militaristas, poniendo la responsabilidad únicamente en estos últimos. ${ }^{10}$

Según Yutaka Yoshida, al menos cuatro grupos dentro de la sociedad japonesa apoyaron esta narrativa: 1) el GHQ y su enorme aparato de propaganda, 2) los miembros de la Familia Imperial, 3) los intelectuales conservadores, y 4) los miembros de los sectores corporativos. ${ }^{11}$ Pese a sus diferencias, todos estos grupos compartían el entendimiento de que el Emperador no tenía ninguna responsabilidad y que la guerra era una conspiración de los militares japoneses. Debido a que esta narrativa fue respaldada por las fuerzas de ocupación estadounidenses y las sucesivas

9 Bonner F. Fellers desarrolla la idea de que los japoneses fueron "engañados por un grupo de militares” como una estrategia para facilitar la ocupación estadounidense durante la posguerra. La estrategia de Fellers se encuentra sucinta en Bonner F. Fellers, "Basic military plan for psychological warfare against Japan” (Manila, Report No. 11-a (15), USSBS Index Section 6, May 1945). Biblioteca digital de la Dieta de Japón, enlace permanente: https://dl.ndl.go.jp/info:ndljp/pid/4009797. 10 Una variante de este discurso es aquella que incluye a Hirohito entre los culpables de haber engañado al pueblo japonés. Véanse los testimonios de los veteranos de guerra Kiyoshi Watanabe 渡辺 清 en Kudakareta kami aru fukuin-bei no shuki 砕かれた神ある復員兵の手記 [Un dios hecho pedazos, diarios de un soldado desmovilizado] Tokio: Iwanami, (1949/2004) y Kenzo Okuzaki en el filme Yuki Yukite Shingun ゆきゆきて、神軍 (1987) del director Kazuo Hara. 11 Yutaka Yoshida, Nibonjin no sensōkan, 2005. 
administraciones conservadoras japonesas luego de la independencia, no es de extrañar que este discurso ganase predominio y formidable visibilidad en la sociedad japonesa hasta el punto de que algunos estudiosos la han llamado "el consenso conservador que abarcaría todas las formas oficiales de construcción de la historia nacional". ${ }^{22}$

"Justificación" (daitōasensō kōtei-ron) comprende los intentos de justificar la expansión japonesa desde finales del siglo XIX, que desencadenó en la participación de Japón en la Segunda Guerra Mundial del lado de las potencias del Eje. Este discurso ha sido también llamado "la Gran Guerra de Asia Oriental fue una guerra justa” en lengua japonesa e incluye, al menos, dos variantes: a) la teoría de la liberación de Asia y b) la teoría de la inevitabilidad de la guerra. ${ }^{13}$

La primera subcategoría sostiene que Japón estaba librando una guerra por la liberación de Asia del yugo de la tiranía occidental, mientras que la segunda sostiene que después del embargo de petróleo de 1941 por parte de los Estados Unidos, al que más tarde se sumaron los británicos y los holandeses, Japón no tuvo más remedio que ir a la guerra. Para algunos líderes

12 Carol Gluck "The Past in the Present", en Postwar Japan as History, ed. por Andrew Gordon (California: University of California Press, 1993), 64-95, 9. La "responsabilidad de los líderes" fue la narrativa oficial del Estado en el primer libro de texto de historia para niños publicado por el Ministerio de Educación de Japón. Véase: Ministerio de Educación de Japón, Kuni no Ayumiくにのあゆみ (Tokio: Tōkyōshoseki, 1946).

$13 \mathrm{El}$ referente más famoso de esta posición es Fusao Hayashi, quien fue corresponsal de guerra en China después del estallido de la segunda guerra sino-japonesa. Su libro Daitōasensō kōtei-ron 大東亜戦争肯定論 [La Gran Guerra de Asia Oriental fue una guerra justa] (Tokio: Chūōkōronshinsha, 1963/2014) recopila las tesis del discurso de "Justificación" que serán repetidas por los nacionalistas de los años noventa. Notables críticas a esta narrativa se encuentran en las obras de Keichi Eguchi 江口 圭一, Nibon fashizumu no keisei 日本ファシズムの形 成 [La formación del fascismo japonés] (Tokio: Nihonhyōronsha, 1978) y Jü go$n e n s e n s o ̄ s h o s h i$ 十五年戦争小史 [Historia concisa de la guerra de los 15 años] (Tokio: Aoki Shoten, 1991). 
japoneses de la época "la Gran Guerra de Asia Oriental fue una guerra de 100 años contra el colonialismo occidental, y después del 'accidente' del Puente de Marco Polo, fue una guerra defensiva”. ${ }^{14}$

La teoría de la liberación de Asia fue la narrativa oficial antes y durante la guerra. Muchos de los líderes militares -y no pocos civiles- expresaron en sus memorias que en ese entonces creían firmemente que el imperialismo japonés era noble y panasiático, expresado en el lema "Asia para los asiáticos". Su proyecto para "liberar Asia” preveía la creación de un bloque de naciones asiáticas lideradas por japoneses y libres de influencias occidentales a través de la Esfera de Co-Prosperidad del Gran Asia Oriental, una idea que, de hecho, fue apoyada por varios nacionalistas asiáticos. ${ }^{15}$

El discurso que sostiene la "inevitabilidad de la guerra" (yamu wo enakatta) explica que la Gran Depresión, cuyos efectos resonaron hasta finales de la década de 1930, hizo que los militares tomaran conciencia de la vulnerabilidad de Japón a las influencias externas y pusieran la necesidad de asegurar fuentes de alimentos, materias primas y combustible como una prioridad. Debido a esa escasez, según la lógica del discurso, cuando Estados Unidos impuso un embargo petrolero en 1941, seguido por los británicos y los holandeses -después de que Japón ocupara el sur de la Indochina francesa- "Japón se quedaría sin petróleo en un tiempo medible, llevando a un colapso de toda la economía basada en combustibles fósiles" ${ }^{16}$ Luego, después de agotar las medidas diplomáticas, asfixiado por el bloqueo económico de las potencias occidentales, Japón no tuvo más remedio que ir a la guerra.

El tercer discurso, "imperialismo japonés” (nibon no teikoku shugi), denuncia explícitamente a este como la causa principal de la guerra en Asia. Destaca los actos de perpetración, invasión y explotación de Japón

14Gluck, "The Past in the Present", 84.

15 Sobre el apoyo de algunos nacionalistas e independentistas asiáticos a la idea de la Esfera de Co-Prosperidad del Gran Asia Oriental, véase: Ian Dear y Michael R. D. Foot, The Oxford Companion to World War II (Oxford: Oxford University Press, 1995), 844-845.

16Ian Dear y Michael R. D. Foot, The Oxford Companion to World War II, 845. 
en China, Corea y el sudeste asiático, que algunos han llamado el "oscuro descenso al infierno", el "camino al fascismo" o "la guerra de 15 años de agresión". ${ }^{17}$ Los partidarios de esta narrativa afirman que el fascismo y la guerra no fueron accidentes, sino que tenían raíces estructurales en la sociedad japonesa que eligió el militarismo, un camino hacia el imperialismo y el colonialismo que se puede rastrear hasta la anexión del Reino de Ryūkyū a través de la Disposición de 1876-9. Estos autores indican que después de la Restauración Meiji, Japón llevó a cabo varias políticas imperialistas que terminaron en la guerra sino-japonesa y la anexión de Formosa (1895), la guerra ruso-japonesa (1905), la anexión de Corea (1910), el sitio de Tsingtao (1914), la segunda guerra sino-japonesa (1937-1945) y el estallido de la guerra del Pacífico (1941-1945). ${ }^{18}$

Este punto de vista sobre la historia reconoce la responsabilidad de Japón como agresor con respecto a los pueblos occidentales y asiáticos antes y durante la II Guerra Mundial, además de que hace hincapié en las atrocidades cometidas por el Ejército japonés, como la Masacre de Nanjing, las "mujeres de consuelo" y los experimentos con armas químicas y biológicas en seres humanos realizados por la infame Unidad 731 en Manchuria. El historiador Saburo Ienaga describió la guerra como "una

17 La expresión el "oscuro descenso al infierno" aparece en John W. Dower, Embracing Defeat, 1999; “el camino al fascismo”, en Tsutomu Ōuchi 大内 力, Nibon'norekishi, 24: fashizumu e no michi 日本の歴史〈24〉ファシズムへの道 [El camino al fascismo: Historia de Japón vol. 24] (Tokio: Chūkō bunko, 2006); "la guerra de agresión de 15 años", en Keiichi Eguchi, Jù go-nen sensō shoshi y en Saburō Ienaga 家永三郎, Taiheiyōsensō 太平洋戦争 [La Guerra del Pacífico] (Tokio: Nihonrekishisōsho 1968).

18 Una exquisita explicación del expansionismo japonés desde sus inicios se encuentra en Eiji Oguma 小熊 英二, 'Nibonjin'no kyōkai: Okinawa Ainu Taiwan Chōsen shokuminchi shibai kara fukki undō made「日本人」の境界一沖縄・ア イヌ・台湾・朝鮮 植民地支配から復帰運動まで [Las fronteras de 'los japoneses': Okinawa, Ainú, Taiwán y Corea] Tokio, Shinyosha, 1998). Una versión al inglés ha sido traducida por Leonie R. Stickland, The Boundaries of "The Japanese": Okinawa 1818-1972 Inclusion and Exclusion (Tokio: Trans Pacific Press, 2014). 
agresión ilegal, injusta e imprudente que duró quince años" ${ }^{19}$ Este discurso se enmarca muchas veces en una interpretación marxista de la historia y en la memoria pública como una afronta a la memoria institucional, "contra-memoria" o "historia como oposición". Fue muy popular en la sociedad japonesa entre 1946 y 1948 y luego entre 1972 y 1995 , pero perdió fuerza después del reavivamiento del nacionalismo japonés durante la década de $1990 .^{20}$

\section{Modalidades discursivas de representación: más allá del esquema tripartito de víctimas, héroes y perpetradores}

En la sección anterior se explicó que el examen de diversas fuentes primarias corrobora la existencia de tres narrativas predominantes acerca de las causas que llevaron a Japón a involucrarse en la II Guerra Mundial, tratadas ya en la literatura académica. Con respecto a la representación de las personas que vivieron durante ese periodo, la literatura académica suele detenerse en una categorización tripartita de "víctimas", "héroes" y "perpetradores". ${ }^{21}$ Por ejemplo, el enfoque etnocéntrico en conmemorar únicamente a las víctimas japonesas se ha llamado "conciencia de víctima" (victim consciousness o higaishaishiki), mientras que la denuncia de los

\section{Saburō Ienaga, Taiheiyōsensō, 2-13.}

20 Interpretaciones marxistas de los orígenes de la guerra se encuentran en Kiyoshi Inoue 井上 清, Nibon teikoku shugi no keisei 日本帝国主義の形成 [La formación del imperialismo japonés] (Tokio: Iwanami Shoten, 1968/2001) y Shiso Hattori 服部之総, Hattori shisō zenshū nibon teikoku shugiron 服部之総 の服部之総全集〈19〉日本帝国主義論 [Teorías sobre el imperialismo japonés] (Tokio: Fukumura Press, 1974).

21 Por representación se entiende el proceso de poner en forma concreta un concepto ideológico abstracto de grupos y comunidades (mujeres, trabajadoras, chinos, japoneses) en productos y textos mediáticos (películas, libros, periódicos, etc.), de acuerdo con la percepción que el productor de los textos tiene sobre lo representado. Véase: Tim O'Sullivan et al., Key Concepts in Communication and Cultural Studies (London: Routledge, 1994): 265. 
crímenes cometidos por el Ejército japonés se ha catalogado como "conciencia de perpetrador" (perpetrator consciousness o kagaishaishiki). Asimismo, es común encontrar una representación heroica de los soldados japoneses sin reparar en sus crímenes, lo que puede llamarse "conciencia heroica". ${ }^{22}$

Sin embargo, el análisis de la literatura primaria indica que el esquema de categorización en "héroes, víctimas o perpetradores" utiliza términos demasiado amplios, omitiendo importantes matices bajo un mismo concepto. ${ }^{23}$ Por ejemplo, a pesar de ser tratado habitualmente bajo el término

$22 \mathrm{El}$ uso de los conceptos "conciencia de víctima" y "conciencia de perpetrador" puede consultarse en inglés en Dower, Ways of Forgetting, 2012 y en japonés en Yoshida, Nihonjin no sensōkan, 2005. La inclusión de la categoría de "conciencia heroica" ha sido desarrollada por Joseph J. Orr, The victim as hero ideologies of peace and national identity in postwar Japan (Honolulu: University of Hawai' $i$ Press, 2017) y Akiko Hashimoto, The Long Defeat, 2019.

23 Algunos ejemplos de las fuentes primarias consultadas con respecto a la representación de las personas que vivieron la II Guerra Mundial son las obras del círculo literario Buraiha (無頼派) entre los que destacan Daraku-ron 堕落論 [Teoría de la decadencia] (1946) de Ango Sakaguchi, Nikutai no mon 肉体の門 [Las puertas de la carne] (1947) de Taijiro Tamura y Shayo斜陽 [El ocaso] (1947) de Osamu Dazai. También se examinaron los testimonios de civiles que sobrevivieron a la guerra compilados en el periódico Asahi como Sensō chi to namida de tsudzutta shōgen 戦争 血と涙で綴った証言 [Testimonios de guerra escritos con sangre y lágrimas] (1987) y On’na-tachi no taiheiyosensō 女たちの太平洋戦争 [Las mujeres de la Guerra del Pacífico] (1996) y los testimonios de los supervivientes a la bomba atómica en Hiroshima recopilados por la Asociación de la Ciudad de Hiroshima en Genbaku taiken-ki 原爆体験記 [Archivo de experiencias de la bomba atómica] (1975). Particularmente reveladoras fueron las últimas cartas de los pilotos de las Fuerzas Especiales de Ataque ('Kamikazes') en Kiyomi Morioka, Wakaki tokkōtai-in to taiheiyōsensō: sono shuki to gunzō 若き特攻隊員と太平洋 戦争その手記と群像 [Jóvenes de las unidades de ataque especiales y la Guerra del Pacífico: Memoria e imagen] (2011) y los 'best sellers' de Masanobu Tsuji 辻 政信, coronel y estratega del Ejército Imperial Japonés, Jū go tai ichi: Biruma no shitō十五対一 -ビルマの死闘 [Quince contra uno: Lucha a muerte en Birmania] 
general "conciencia de víctima", la victimización ingenua de quienes repiten frases como "debemos orar por la paz", sin mencionar el contexto de lo que provocó esa guerra, no es comparable a la de quienes afirman que todas las demandas de paz deben hacerse bajo la premisa de que Japón no solo fue víctima sino también victimario y, buscando reconciliación con las víctimas de otras naciones, participan en movimientos globales como la Campaña Internacional para Abolir las Armas Nucleares (ICAN) que en 2017 ganó el Premio Nobel de la Paz. De la misma manera, los discursos que reconocen los actos de perpetración en el lado japonés tienden a usar palabras como "responsabilidad", "remordimiento" y "culpa" sin hacer diferencias elementales entre generaciones, el grado de participación en los actos criminales, y muchas veces repitiendo el estereotipo de que los japoneses presentes, pasados y futuros forman un colectivo uniforme que comparte una "esencia" y, por lo tanto, tienen una responsabilidad directa. Este trabajo pretende mostrar esos matices y prestar atención a sus implicaciones neonacionalistas.

\section{Conciencia de víctima}

Este discurso enfatiza el sufrimiento de las víctimas japonesas mientras ignora, minimiza o, incluso, niega la miseria que vivieron las personas de otros países. Normalmente se presenta al lado del discurso que adjudica toda la responsabilidad a los líderes, aseverando que los militares obligaron al pueblo a una guerra imprudente. ${ }^{24}$ La guerra se representa como algo que les sucedió a los japoneses sin contexto -como un desastre natural-, en lugar de algo en lo que participaron. Por eso, algunas investigadoras han bautizado a esta manera

(1950) y Shingapōru - unmei no tenkiシンガポール -運命の転機 [Singapur: un punto de inflexión en el destino] (1952).

$24 \mathrm{La}$ idea de que todos los civiles japones fueron engañados por una camarilla de líderes militaristas ha sido desmentida en investigaciones que exponen el entusiasmo y las contribuciones voluntarias del sector civil ya no solo al esfuerzo de la guerra, sino a detonarla. Véase: Louise Young, Japan's Total Empire: Manchuria and the Culture of Wartime Imperialism (California: University of California Press, 1998). 
de contar la historia como "la historia en voz pasiva" o "la narrativa de la catástrofe". ${ }^{25}$

Antes de proseguir es necesario hacer una aclaración: las críticas a la conciencia de víctima no niegan que en Japón haya habido innumerables víctimas inocentes. Millones de personas que sufrieron durante esos años eran demasiado jóvenes para haber participado en cualesquiera de los crímenes que se adjudican al colectivo, los medios nacionales nunca informaron de los actos reprobables del Ejército japonés y muchos de los soldados fueron reclutados a través de un sistema de conscripción universal. ${ }^{26}$ Se estima que en 1945 , cuando el número de víctimas se disparó por causa de los bombardeos aliados contra ciudades japonesas, el 36,8 \% de la población (26 millones) tenía entre 0 y 14 años. El estricto control del sistema educativo y los medios de comunicación tuvo como consecuencia que, para esa generación, la II Guerra Mundial fuera en efecto una catástrofe sin trasfondo histórico, algo así como un "desastre natural" que destruyó abruptamente sus vidas y, por lo tanto, es esperable que al conmemorar el evento, lo hagan desde esa perspectiva. ${ }^{27}$ Por esa razón, el término "conciencia de víctima" debe ser usado con cautela, pues no equivale necesariamente a victimización etnocéntrica, sino también a la experiencia concreta de un sinnúmero de individuos inocentes. Sin embargo, lo que parece sospechoso para muchos investigadores son las prácticas de conmemoración que se enfocan conveniente y exclusivamente en esas víctimas inocentes, dejando de lado a aquellas de otras naciones afec-

$25 \mathrm{El}$ concepto de la "historia en voz pasiva" (history in passive voice) fue adelantado por Carol Gluck “The idea of Showa”, Daedalus 119, no. 3, (1990): 1-26; el de la "narrativa de la catástrofe" (catastrophe narrative) aparece en Akiko Hashimoto, The Long Defeat, 7.

26 Para una detallada investigación sobre el control de los medios de comunicación desde el siglo XIX hasta el final de la guerra, véase: Hidetoshi Kuroda 黒田 秀俊, Mono ienu jidai もの言えぬ時代 [La época en la que no se podía hablar] (Tokio: Tosho, 1986).

27 Oficina de Estadística de Japón. Población por Grupo de Edad e Índices de Estructura de Edad (1920- presente). URL: http://www.stat.go.jp/ (Consultado en agosto de 2021). 
tadas precisamente por la agresión japonesa. Tomando esto en cuenta, se presentarán las subcategorías detectadas en el transcurso de esta investigación que, hasta ahora, se han incluido en el término general "conciencia de víctima”. Estas son: (1) Pacifismo activista, (2) Pacifismo ingenuo y (3) Pacifismo mesiánico. ${ }^{28}$

Pacifismo activista. A pesar de que muchas de las campañas pacifistas se centran en el sufrimiento japonés, como el causado por las bombas atómicas y los bombardeos de ciudades japonesas, los portavoces del aquí llamado "pacifismo activista" no han dudado en reconocer los actos de perpetración cometidos por el Ejército japonés en las zonas de Asia que fueron ocupadas. Por el contrario, han utilizado la experiencia japonesa para recordar al mundo la miseria de la guerra como un mal absoluto en la que todos los bandos sufren. Su deseo de contribuir a la paz mundial no se reduce a buenos deseos, sino que han participado activamente en los movimientos antibélicos durante las décadas de 1960 y 1970 y se han trazado objetivos concretos reflejados en la Campaña Internacional para Abolir las Armas Nucleares (ICAN), que recibió el Premio Nobel de la Paz en el 2017. ${ }^{29}$

28 La elaboración de las siguientes subcategorías es responsabilidad exclusiva del autor. La literatura académica se detiene en el esquema tripartito de víctimas, héroes y perpetradores. La parte más desafiante del artículo no fue procesar la gran cantidad de datos, sino tratar de encontrar una manera de minimizar el factor de la subjetividad. El método de análisis de contenido, el análisis narrativo, el proceso de codificación y la consideración de niveles textuales explicados en la metodología buscaban reducir el elemento subjetivo, pero partiendo del entendimiento de que es imposible eliminarlo por completo.

29 Es notable que, aunque muchos de los testimonios consultados pertenecen a personas que no conocieron el frente de batalla, muchos de ellos se refieren enfáticamente al sufrimiento de otros pueblos, particularmente de China, Filipinas y Corea, diferenciándose así del término general "conciencia de víctima”. En este grupo destacan las sobrevivientes de los ataques nucleares Setsuko Thurlow (1932-), galardonada con el Premio Nobel de la Paz en 2017 por sus esfuerzos al proyecto del desarme nuclear, y Sadako Kurihara (1913-2005), famosa poetisa 
Pacifismo ingenuo. Debido a la existencia del "pacifismo activista", es difícil no encontrar una diferencia fundamental con quienes expresan su deseo de alcanzar la paz solamente orando. Este tipo de discurso se encuentra en aquellas conmemoraciones bajo el mantra de "orar por la paz" (beiwa no tame ni inoru) que no proporcionan ningún tipo de contexto histórico sobre las condiciones que llevaron a la guerra, ni mencionan a las víctimas de otras naciones, así como tampoco se esfuerzan en analizar aquellos elementos de racismo, intolerancia y nacionalismo que prevalecieron en ambos frentes durante la guerra. Como la principal característica de esta modalidad discursiva es ignorar a las víctimas en otras naciones, varios académicos han llamado a lo que aquí se expone como "pacifismo ingenuo" con términos como la "historia en voz pasiva", "la narrativa de la catástrofe", "evasión" o "ausencia de Asia". ${ }^{30}$

Pacifismo mesiánico. Este tipo de discurso debe entenderse como la creencia de que el sufrimiento causado por la Guerra tenía el significado trascendental de lograr la paz mundial. En este sentido, la agonía de

que retrató la tragedia de la bomba arrojada en Hiroshima partiendo de una profunda reflexión sobre los crímenes cometidos por el Ejército japonés en Filipinas, China y Pearl Harbor. Su poema "Cuando decimos Hiroshima" publicado en 1976 se puede considerar un ejemplo de esta forma de contar la historia.

$30 \mathrm{La}$ frase "rezar por la paz" es recurrente en las transmisiones televisivas, editoriales de periódicos y discursos de políticos japoneses. Otros ejemplos del "pacifismo ingenuo" aparecen en la literatura que proliferó entre el fin de los años cuarenta y el decenio de 1950, considerada por algunos "literatura pacifista" por su deseo de lograr la paz, pero criticada por otros porque ignora el sufrimiento de otros pueblos. La novela Biruma no tategoto ビルマの竪琴 [El arpa birmana] de Michio Takeyama, que más tarde sería llevada al cine y se convertiría en película de culto, evita mencionar la miseria de las personas de Myanmar, aunque su historia está situada en medio de la Campaña de Birmania (hoy Myanmar) - que cobró la vida de entre un cuarto y un millón de civiles-. En cambio, muestra a soldados japoneses interactuando amistosamente con los locales y a un protagonista descrito como un santo que, aún terminada la guerra, desiste de regresar a casa para dedicarse a rezar por las almas de sus compañeros fallecidos. 
los japoneses serviría para guiar a la humanidad a una nueva era. Esta interpretación se articuló en la novela Las campanas de Nagasaki, escrita por el cristiano y hibakusha Takashi Nagai (1908-1951), quien presentó a las víctimas de la bomba atómica (incluido él mismo) como sacrificios ofrecidos en holocausto a Dios para obtener la bendición del final de la guerra y el lanzamiento de las bombas como necesario para "expiar la ira de Dios". ${ }^{31}$ Durante la década de 1950, muchas novelas orientadas a los nińos contribuyeron a la idea de que la paz de la posguerra se debía al sacrificio de las víctimas japonesas. Este enfoque escatológico se ha reproducido en ensayos filosóficos, editoriales de periódicos, libros y películas hasta el presente. ${ }^{32}$

31 Nagai expone su interpretación del sentido escatológico de la guerra como sigue: “¿No existe una relación profunda entre el final de la Guerra y la destrucción de Urakami (Catedral de Nagasaki)? ¿No es Urakami, el único templo de Japón, elegido como un cordero sin mancha para ser sacrificado en el altar, como compensación por la culpa de la última guerra? (...) Cuando Urakami fue ofrecida en holocausto, Dios lo aceptó, escuchó las disculpas de la humanidad y dio una revelación a Su Majestad el Emperador para que tomase la sagrada decisión de terminar la Guerra (...) Este sacrificio ha salvado a decenas de millones de personas que habrían de sufrir por causa de más guerras en el futuro" [mi traducción]. Original: 終戦と浦上潰滅との間に深い関係がありはしないか。世界大戦 争という人類の罪悪の償いとして、日本唯一の聖地浦上が犠牲の祭壇に 屠られ燃やさるべき潔き羔として選ばれたのではないでしょうか？ (...) 然 るに浦上が屠られた瞬間初めて神はこれを受け納め給い、人類の詫びを きき、忽ち天皇陛下に天啓を垂れ、終戦の聖断を下させ給うたのでありま す。この羔の犠牲によって、今後更に戦禍を蒙る筈であった幾千万の人久 が救われたのであります。Takashi Nagai, Nagasaki no Kane [Las campanas de Nagasaki] (Tokio: San Paulo Editorial, 1949), 175.

32 Kiyoteru Tsutsui utiliza el concepto "evasión” para describir una idea muy similar. Para ilustrarlo, cita un editorial de 15 de agosto de 1995 del periódico Mainichi Shimbun que reza: "Tenemos que recordar que la paz y la libertad que disfrutamos hoy se basa en el sacrificio de más de 7 millones de compatriotas japoneses”. Kiyoteru Tsutsui, “The Trajectory of Perpetrators", 1400. John W. Dower sugiere que el concepto de "arrepentimiento radical” (zange), del filósofo Hajime 


\section{Conciencia de perpetrador}

El discurso que aquí se denomina como "conciencia de perpetrador" (kagaisha ishiki) normalmente viene asociado con una crítica al imperialismo japonés como causa de la guerra, mencionada en la sección anterior. Esta "conciencia de perpetrador" enfatiza los crímenes del Ejército japonés durante la Segunda Guerra Mundial y extiende la responsabilidad a las asociaciones civiles, las corporaciones financieras, los medios de comunicación y los intelectuales que respaldaron el esfuerzo bélico.

Durante las primeras décadas de la posguerra, este tipo de discurso fue monopolio de un pequeño número de intelectuales progresistas y algunos soldados rasos, pero en la década de 1970 ganó visibilidad después de la publicación de la serie de artículos Viajes en China por el periodista Katsuichi Honda, que revelaron detalles sobre la Masacre de Nanjing en el periódico de alta circulación Asabi Shimbun. ${ }^{33}$ En la década de 1980, muchos soldados veteranos comenzaron a confesar sus crímenes en Asia luego de haber alcanzado una edad avanzada, lo cual coincidió con veredictos favorables a las demandas del historiador Saburō Ienaga de incluir

Tanabe, incluye elementos mesiánicos, como la idea de que Japón tenía la misión de usar su experiencia para guiar a la humanidad por el camino de la paz entre los extremos del capitalismo y el comunismo, John W. Dower, Embracing Defeat, 499-500.

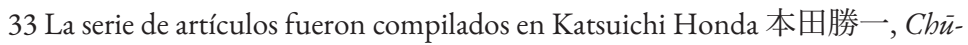
goku no tabi 中国の旅 [Viajes en China] (Tokio: Asahi Shimbun editorial, 1972). Las confesiones de los soldados veteranos fueron publicadas en la revista Ushio en el proyecto especial llamado "Crímenes cometidos por japoneses en China continental” que reunió más de cien testimonios. Entre 1981 y 1987 se publicaron abundantes libros autobiográficos o con testimonios de los agresores. Uno de los más famosos es Akuma no hōshoku 悪魔の飽食 [La gula del diablo] (1981) de Seichi Morimoto. Asimismo, durante ese periodo se produjeron muchas películas que enfatizaban el rol de victimario de Japón como Merry Christmas Mr. Lawrence 戦場のメリークリスマス (1983), Umi to Dokuyaku 海と毒薬 [El mar y el veneno] (1986) y Yuki Yukite Shingun ゆきゆきて、神軍 [El ejército del Emperador marcha desnudo] (1987). 
tales hechos en los libros escolares y la ola de críticas internacionales tras la "controversia de los libros de texto" de 1982. ${ }^{34}$ Esta tendencia alcanzó su clímax cuando fue seguida por disculpas cada vez más explícitas dadas por los primeros ministros japoneses, desde el conservador Yasuhiro Nakasone (1918-2019) hasta el socialista Tomiichi Murayama (1924-). ${ }^{35}$

El análisis de las fuentes primarias sugiere la existencia de cuatro subcategorías: (1) Remordimiento reconciliatorio, (2) Relativización, (3) Remordimiento deuteronómico y (4) Remordimiento intraétnico.

Remordimiento reconciliatorio. Esta variante reconoce los crímenes cometidos por el bando japonés durante la guerra. En la esfera pública suelen presentarse grabaciones de los mismos autores de los hechos, ya sean veteranos o civiles, expresando su remordimiento sin ambigüedades. Esta modalidad discursiva ha sido apropiada por generaciones más jóvenes que enfatizan la naturaleza perversa de los crímenes cometidos por el Ejército japonés, pero sin atribuir esos crímenes a sí mismos en cuanto “japone-

34 La controversia de los libros de texto ocurrió cuando el Ministerio de Educación de Japón sugirió cambiar la palabra "avance" en lugar de "invasión" con respecto a la invasión japonesa de China. Tras las críticas de los medios progresistas japoneses y los gobiernos de las naciones del Este de Asia, el entonces Jefe del Gabinete de gobierno Kiichi Miyazawa (1919-2007) emitió la "Cláusula con relación a países vecinos” (Kinrin shokoku jōkō 近隣諸国条項) en la que el gobierno japonés se comprometía a tratar los acontecimientos históricos respetando la perspectiva de los países asiáticos.

35 Altos funcionarios del gobierno japonés y el emperador Akihito se han disculpado explícitamente por la conducta del Ejército japonés durante la guerra en, al menos, 43 ocasiones desde 1990 hasta el 2019. Un cambio notable, comparado con cuatro disculpas particularmente ambiguas ofrecidas entre 1950 y 1980. Véase: Jane Yamazaki, Japanese Apologies for World War II (London: Routledge, 2006). También se puede consultar The Institute for the Study of Human Rights (ISHR) en Columbia University, Section of Political Apologies. URL: http:// www.humanrightscolumbia.org/ahda/political-apologies (consultado el 10 de setiembre, 2021). 
ses”. Ese reconocimiento de la historia de agresión del Japón (como Estado) ha contribuido al diálogo internacional con otros países asiáticos. ${ }^{36}$ Relativización. Esta estrategia discursiva tiene como característica el reconocimiento de que, si bien algunos crímenes fueron cometidos por algunos japoneses, tales actos criminales fueron mínimos comparados con aquellos cometidos por la otra parte. Por ejemplo, quienes se adhieren a esta narrativa, mencionan la Masacre de Nanjing solo para traer a la discusión la barbarie de los bombardeos atómicos de Hiroshima y Nagasaki. Esta forma de abordar la historia es bastante común en otras naciones, por ejemplo, cuando se habla de la miseria de Hiroshima y Nagasaki, algunos estadounidenses inmediatamente destacan el ataque a Pearl Harbor. En resumen, la relativización es una forma de argumentación que contribuye poco al examen cuidadoso de hechos particulares y participa en juegos retóricos de tuo quoque.

Remordimiento deuteronómico. Este tipo de discurso sigue la sentencia bíblica que ordena: "la iniquidad, la culpa y los pecados de los padres pasan a los hijos hasta la tercera y cuarta generación". ${ }^{37}$ El uso de este concepto es heurístico. En Japón y en varios países del Este de Asia, el remordimiento transgeneracional no se basa en premisas bíblicas sino en un fuerte sentido de identidad con los actos de los miembros pasados, presentes y futuros del colectivo. Por ejemplo, Oda Makoto quien tenía 13 años al final de la guerra, enfatizó: "Esta psicología indulgente llamada 'conciencia de víctima' (...) desdibuja el hecho de que nosotros éramos, en principio, los perpetradores de la guerra" [énfasis añadido]. ${ }^{38}$

36 Ejemplos de esta tendencia se muestran en abundantes cartas de veteranos japoneses publicadas en las secciones Téma danwa-shitsu y Koe en el periódico Asabi y, en menor medida, en la sección Kataritsugu sensō en el periódico Yomiuri.

37 Éxodo 20:5; Números 14:18. El tema se contradice más tarde en Deuteronomio 24:16 y Ezequiel 18:20.

38 Makoto Oda 小田実, Nan shi” no shiso 難死の思想 (Tokio: Iwanami Shoten, 1966/2008) citado en Orr, The victim as hero, 1. Por ejemplo, en el documental Sakura-tai Chiruさくら隊散る (1988), los sobrevivientes de la bomba atómica en Hiroshima recuerdan sus experiencias durante la tragedia al tiempo que afirman también ser "perpetradores" (en cuanto japoneses). 
El remordimiento deuteronómico ha sido omnipresente durante la posguerra en el Este de Asia, por lo que no es raro que japoneses de la tercera o cuarta generación se disculpen con contemporáneos asiáticos por lo que hicieron.

Remordimiento intraétnico. Esta subcategoría indica la tendencia a reconocer y denunciar diversos tipos de agresión durante la guerra por parte de algunos japoneses contra otros japoneses. Por ejemplo, los abusos de los rangos superiores del ejército contra los rangos inferiores o de los militares en perjuicio de los civiles. Sin embargo, los mismos abusos contra personas no japonesas no son representados, reforzando así la idea de que la miseria de la guerra fue algo que les sucedió únicamente a los japoneses. Esta forma de representación es común en la televisión y el cine. ${ }^{39}$

\section{Conciencia heroica}

La "conciencia heroica" ha sido descrita con varios nombres en la literatura académica. En japonés se la ha llamado "visión heroica de la historia" (eiyütan-kan), "embellecimiento de la guerra" (sensō sanbi) o "promilitarismo" (kōsen-sei), mientras que en la literatura en inglés normalmente se la equipara con el nacionalismo tout court. Este discurso tiende a narrar la guerra como una gesta heroica del pueblo japonés y, sobre todo, de los héroes caídos (eirei: literalmente "las almas de los héroes"). ${ }^{40}$

Aunque este tipo de representación fue reprimida durante la ocupación estadounidense, resurgió con fuerza después de que Japón recuperase su independencia y se hizo visible en las conmemoraciones de dos grupos en particular: los veteranos de alto rango de la Armada Imperial Japonesa y los veteranos de alto rango del Ejército. Pese a su abierta rivalidad, la narrativa de los antiguos altos mandos de la Armada y el Ejército compartía elementos de heroísmo y patriotismo aún después de la aplastante

39 Este tipo de representación es visible en las películas Ichimai no hagaki一枚の ハガキ (2011) del director Kaneto Shindo y Otoko-tachi no Yamato 男たちの大 和 (2005) dirigida por Junya Satō.

40 Otros términos usados para describir lo que en este trabajo se llama "conciencia heroica” aparecen en Yoshida, Nibonjin no sensökan, 142. 
derrota. Por ejemplo, las batallas eran representadas de una manera positiva y romántica, destacando el coraje de los soldados y sus líderes, pero evadiendo cualquier sentido de responsabilidad o remordimiento hacia las víctimas de otros países. En cuanto a los orígenes de la guerra, algunos justifican la participación japonesa mientras que otros aceptan el discurso de la "responsabilidad de los líderes" afirmando que, incluso en una guerra imprudente, los soldados y los civiles lucharon con valor.

Este tipo de discurso retrata la guerra misma como un evento "glorioso" o "espectacular" (banabanashi) siguiendo la retórica de la "hermosa guerra" que había sido difundida en la propaganda japonesa desde los años treinta. ${ }^{41}$ Por ejemplo, entre 1946 y 1950, oficiales veteranos del Ejército y las asociaciones de "amigos de la guerra" (sen'yü-kai) inundaron el mercado con publicaciones sobre sus experiencias en la Segunda Guerra Mundial, principalmente relacionadas con la guerra del Pacífico. En estas publicaciones, los autores insistían en que la Gran Guerra de Asia Oriental fue una guerra justa emprendida para liberar Asia y, por lo tanto, los soldados japoneses caídos en batalla fueron héroes que murieron por una noble causa.

En los años sesenta, ese discurso fue retomado por artistas de cómics (manga) y por editores de revistas dirigidas a niños y jóvenes japoneses. Las narraciones centraban su interés únicamente en las armas como dispositivos tecnológicos, pero no proveían contexto histórico de cómo fueron usadas. Asimismo, en lugar del combate cuerpo a cuerpo, solo se exhibían escenas con aviones de combate, buques de guerra y portaaviones. Esto implicaba que no fueron las sangrientas batallas libradas por el

41 Para 1948 ya se había fundado la revista sobre temas militares Maru y para 1955, los veteranos de la Armada Imperial Japonesa ya tenían su propia revista: Nibon rikukaigun no sōkessan zasshi $i$ 日本陸海軍の総決算雑誌. Un ejemplo de estas memorias son el ya mencionado opus magnus de Takushiro Hattori, Daitōasensō zenshi, 1953 y los libros de Masanobu Tsuji, Jü go tai ichi: Biruma no shitō y Shingapōru - unmei no tenki. A esta narrativa también se pueden sumar las memorias de conocidos ultranacionalistas como Sasagawa Ryochi (1899-1995) y Kodama Yoshio (1911-1984), quienes escribieron desde la prisión de Sugamo. 
ejército terrestre en las selvas de Asia las presentadas a los niños, sino las batallas impersonales entre aviones y buques durante la Guerra del Pacífico, expuestas como una "competencia deportiva" o un "juego infantil". En el mismo movimiento, los episodios de la guerra fueron presentados, cuando fue posible, como "grandes victorias" de Japón (por ejemplo, Pearl Harbor), explicando que la eventual derrota fue circunstancial y no estructural, es decir, Japón perdió por carecer de recursos naturales pese a tener mejores armas y soldados. ${ }^{42}$ Durante las décadas de 1970 y 1980 , la "conciencia heroica" fue de alguna manera eclipsada por "la conciencia de perpetrador", pero fue revivida a finales de la década de 1990 y el siglo XXI por grupos ultranacionalistas que insisten en reivindicar el "espíritu de lucha" (kantó seishin) de los soldados japoneses y el deber de recordar "las valientes batallas libradas por nuestros abuelos". ${ }^{3}$

El análisis de la literatura primaria mostró la existencia de tres variantes principales de esta "conciencia heroica": (1) el héroe trágico, (2) el héroe patético y (3) el héroe victorioso.

El héroe trágico. Esta forma de representación se refiere al héroe que da su vida por una causa noble. Aún luego de la derrota, las abundantes metáforas

42 Un estudio sobre esta narrativa bélica en las revistas dedicadas a niños durante los años sesenta puede consultarse en Yoshinori Takahashi 高橋 由典, “1960 nendai shōnen shūkanshi ni okeru 'sensō' shōnen magajin no jirei”一九六 $\bigcirc$ 年代少 年週刊誌における「戦争」「少年マガジン」の事例en Sengonibon no naka no 'sensō', ed. por Hisao Naka (Tokio: Sekai shisō-sha, 2004): 181-212. Un análisis de la reconstrucción de la imagen de la guerra en los comics japoneses se desarrolla en Fusanosuke Natsume 夏目房之介, Manga to 'sensō’ マンガと「戦争」(Tokio: Kodansha, 1997).

43 La cantidad de publicaciones que repiten esta narrativa es demasiado cuantiosa para abordarla en el presente estudio. Las tesis de dos de los más activos y reconocidos defensores de la "conciencia heroica" se encuentran en Nobukatsu Fujioka 藤岡信勝, Ojoku nokingendai-shi 污辱の近現代史——いま、克服のと き [Ahora es el momento de vencer la historia moderna de humillación] (Tokio: Tokuma Shoten, 1996) y Yoshinori Kobayashi, Sensōron 戦争論 [Teorías sobre la Guerra] (Tokio, Gentosha, 1998). 
de lealtad, persistencia y honor del folclor japonés que retrataban el ideal del héroe trágico fueron reacomodadas en la figura del soldado japonés, principalmente en aquellos pertenecientes a las Fuerzas Especiales de Ataque ('kamikazes'). En la esfera pública y la industria del entretenimiento es común que se los describa como valientes (yümō), hermosos (utsukushī) y masculinos (otokorashiku) héroes, mientras que en algunos casos, su "sacrificio y sentido del honor" han sido deificados. ${ }^{44}$ Un importante correlato del héroe trágico es que, como su muerte debe ser motivada por una causa noble, su representación debe enmarcarse en períodos en los que Japón estaba en una situación desesperada y no cuando conducía la agresión. ${ }^{45}$

El héroe patético. Una variante del héroe trágico es el que no es admirado sino ridiculizado: el héroe patético. En la tragedia griega, así como estaban Hércules (epítome del héroe victorioso) y Aquiles (el héroe trágico), también estaba Thersites, un personaje lleno de defectos, que luchaba por lo que consideraba loable, aunque siempre fracasaba crasamente. En Japón, algunos han señalado al hoganbiki como un héroe con el que el espectador no se identifica por sus logros sino por su fragilidad y su inevitable fracaso, así como por el sentimiento de piedad que inspira su solitaria muerte. ${ }^{46}$

44 Kobayashi menciona que los pilotos de las Fuerzas Especiales de Ataque eran jóvenes héroes que sacrificaron sus vidas para proteger a la patria, a sus hogares, a la familia y al emperador y que, a pesar de que la sociedad actual inculca el individualismo, los pilotos kamikaze son el ideal para instar el orden moral basado en individuos al servicio de la sociedad, Yoshinori Kobayashi, Sensōron, 18-19, 37-38, 44,50 .

45 Akiko Hashimoto ha remarcado el hecho de que para que los "kamikazes" puedan ser presentados como "hombres buenos en situaciones malas que no tenían otra opción (...) las historias deben comenzar después de 1941 y representar la guerra contra los Estados Unidos en lugar de China. Si la historia de Miyabe (el protagonista de The Eternal Zero, 2013) hubiera comenzado antes de 1941 durante su despliegue en China, bien podría haber sido mostrado como uno de los pilotos que llevaban a cabo bombardeos indiscriminados contra civiles, como el infame ataque aéreo a la ciudad de Chongqing”. Hashimoto, The Long Defeat, 77.

46 La metáfora del hoganbiki como héroe patético aparece en Orr, The victim as Hero, 2017. 
Varios ejemplos de este héroe patético aparecen en el cine japonés ( $Z e$ gen, de 1987; To the Fields, to the Hills, to the Beaches, de 1986), donde los militares no son representados como figuras heroicas sino ridiculizados, descritos como seres irracionales y fanáticos, seguidores de una ideología moribunda de la que los protagonistas quieren deshacerse. Esto arroja luz sobre el hecho de que la narración heroica ha sido utilizada por grupos críticos del nacionalismo para hacer mofa de ella.

El héroe victorioso. En el Japón de la posguerra, en algunos productos de la industria cultural, el sentido del coraje y el sacrificio de algunos "héroes" no solo se reafirma y se exalta, sino que termina en victoria. ¿Cómo es posible crear un héroe victorioso al recordar una guerra de agresión que terminó en un total fracaso? La respuesta está en el mundo de la ciencia ficción. Algunas producciones articulan su trama en un universo paralelo que nunca se registró en la historia, por ejemplo, retratando a la tripulación de un submarino avanzado - provisto por la Alemania nazi- que salva a Tokio de una tercera bomba atómica (Lorelei: La bruja del Océano Pacífico, 2005), mientras en otros casos, los protagonistas regresan al pasado para comandar en persona al Ejército japonés y poder ganar la guerra. ${ }^{47}$

\section{Discusión: implicaciones neonacionalistas}

Algunas formas colectivas de conmemoración son casi indistinguibles del credo neonacionalista, tales son los casos de la "conciencia heroica" y la narrativa de "justificación" presentadas en las secciones anteriores. Sin embargo, algunos discursos en torno a las causas de la guerra como la "responsabilidad de los líderes” y las modalidades de representación “conciencia de víctima" y "conciencia de perpetrador" también tienen derroteros

47 El primer análisis de esta manera de representar una "victoria” en el universo ficticio del cine está en Aaron Gerow, "Fantasies of war and nation in recent Japanese cinema”, Japan Focus IV, no. 2 (2006). Otro ejemplo se encuentra en Sensōron de Yoshinori Kobayashi donde el protagonista (que es el autor mismo) retrocede en el tiempo para tomar el liderazgo del Ejército japonés y cambiar el curso de la guerra. 
nacionalistas que suelen pasar inadvertidos. En esta sección se expondrán tales implicaciones.

\section{Sobre los orígenes de la guerra}

El discurso de la "responsabilidad de los líderes" tiene un problema elemental: el expansionismo japonés no se basó en una conspiración premeditada de los líderes, sino que avanzó a través de consejos de guerra, que casi nunca llegaban a un consenso. Entre las implicaciones de adoptar este discurso se encuentra su relación con la "conciencia de víctima" en su variante "pacifismo ingenuo" que olvida la agresión del Ejército japonés en Asia y el entusiasmo patriótico por el expansionismo japonés manifestado por un sinnúmero de civiles antes del surgimiento del estado totalitario.

Además, entre las críticas se incluyen lo que se ha llamado el "doble estándar" y la "lógica de la irresponsabilidad". Si bien el discurso de la "responsabilidad de los líderes" proporcionó la atmósfera para la reconciliación entre el pueblo japonés y las fuerzas de ocupación y a pesar de que, de alguna manera, sentó las bases para los movimientos pacifistas que surgieron en las décadas siguiente, algunos autores han argumentado que también ayudó a crear un "doble estándar" en la política japonesa de posguerra: reconocer que la Segunda Guerra Mundial fue una guerra de agresión liderada por una camarilla militar y el compromiso de restablecer relaciones diplomáticas con los estados-nación asiáticos, pero sin un plan nacional serio para instruir a los japoneses sobre las causas de la guerra, prevenir el nacionalismo y reflexionar sobre los crímenes cometidos en nombre del país. ${ }^{48}$ Por su parte, la "lógica de la irresponsabilidad" implica que si aquellos que daban órdenes al final de una cadena de mando eran indultados -el emperador Hirohito y muchos altos mandos del ejército fueron absueltos-, aún más inocentes tendrían que ser aquellos que simplemente seguían esas órdenes. Esto no solo ignora la dosis de culpa de los crímenes que fueron cometidos por los rangos medios y bajos del ejército, sino que olvida el hecho de que numerosos civiles apoyaron entusiasma-

$48 \mathrm{El}$ concepto del "doble estándar" es desarrollado por Yoshida, Nibonjin no sensōkan, 91 . 
damente la guerra, hasta el punto de que algunos historiadores han argumentado que los políticos japoneses de ese momento, antes que un plan premeditado de conquista, se aventuraron en la guerra en China porque no pudieron contener los ánimos nacionalistas de la opinión pública después de que se divulgó la noticia de la invasión de Manchuria. ${ }^{49}$

En cuanto al discurso de "justificación”, el principal obstáculo para contradecir esta narrativa es el hecho de que el imperialismo occidental tenía subyugada a casi toda Asia en ese momento. Lo que los partidarios de esta narrativa tienden a ignorar es que, después de haber sido recibidos como salvadores en países asiáticos como Indonesia y Myanmar, algunos miembros del Ejército japonés comenzaron a discriminar y abusar de los lugareños, cometiendo crímenes aún más viciosos que aquellos que estaban tratando de erradicar. ${ }^{50}$ Finalmente, los defensores de la narrativa de liberación olvidan que los sentimientos antijaponeses generalizados en China después del Movimiento del Cuatro de Mayo fueron reacciones a las Veintiuna exigencias (1915), así como el bloqueo económico de las potencias occidentales fue una reacción a la invasión japonesa de China y la Indochina francesa.

\section{Sobre la representación}

El discurso que pone de relieve el heroísmo de los soldados y civiles japoneses -con la excepción del "héroe patético" - parte del entendimiento de que los héroes, en cuanto tales, luchan por causas nobles. Las escenas que recrean al heroico piloto kamikaze dando su vida por la patria no presentan a los mismos pilotos bombardeando ciudades chinas; las batallas no se presentan como matanzas, sino como oportunidades para alcanzar la gloria y el honor y, en el cine, la televisión y las historietas, la guerra se presenta como una película de acción para el entretenimiento de masas. Asimismo, como la representación heroica de la guerra no se alinea con la

49 Esta interpretación es desarrollada en Ezra F. Vogel, China and Japan Facing History (Cambridge: Harvard University Press, 2019), particularmente en los capítulos 6 y 7.

50 Para un detalle de esos abusos véase: Toland, The Rising Sun, 447-448. 
representación del soldado obligado a luchar contra su voluntad, no es de extrañar que oculte la realidad histórica de la conscripción militar. El heroísmo del piloto kamikaze, el capitán que se niega a rendirse, y las cargas banzai contra el enemigo sugieren erróneamente que todos los japoneses participaron voluntariamente en la guerra.

Por otro lado, aquellos discursos que se enfocan en el sufrimiento del pueblo japonés también tienen derroteros nacionalistas. Si bien la variante "pacifismo activista” en la llamada "conciencia de víctima” ha demostrado tener consecuencias favorables para el desarme nuclear y la reconciliación entre las naciones asiáticas, las variantes "pacifismo ingenuo" y "pacifismo mesiánico" han contribuido poco al diálogo internacional y, en algunos casos, han avivado sentimientos antijaponeses en toda la región debido a su exclusión de otros asiáticos en el recuento de las víctimas de la guerra.

El mayor peligro de estas narrativas radica en su apropiación por parte de los populistas. Existen ejemplos históricos de cómo una autopercepción del colectivo como víctima puede caer fácilmente en una espiral de ultranacionalismo, colocando sentimientos de venganza por injusticias pasadas y el deber de restaurar el prestigio de la patria como pilares de la identidad nacional. Un típico paradigma de esto se muestra en los discursos de Hitler en los que enfatizaba la victimización de Alemania por parte de sus enemigos y acusaba al pueblo judío de ser el victimario. Estudios recientes indican una relación entre las narrativas de victimismo y el renacimiento de formas agresivas de nacionalismo en Ruanda, Burundi, Israel y Corea del Sur. ${ }^{51}$ En Japón, esta "conciencia de víctima” ya ha sido

51 El uso de la narrativa de la victimización de Alemania por la propaganda nazi y por el mismo Hitler está desarrollado en George Victor, Hitler: The Pathology of Evil (Nebraska: Potomac's Paperback Classics, 1999). Sobre los estudios que relacionan la victimización con el nacionalismo, véase: Johanna Ray Vollhardt, "The Role of Inclusive and Exclusive Victim Consciousness in Predicting Intergroup Attitudes: Findings from Rwanda, Burundi, and DRC”, Political Psychology, XXXVI, no. 5 (2015): 489-506; Daniel Bar-Tal, Intractable Conflicts: Socio-Psychological Foundations and Dynamics (Cambridge: Cambridge University Press, 2013) y Mikyoung Kim (ed.), Routledge Handbook of Memory and Reconciliation in East Asia (Abingdon: Routledge, 2015). 
utilizada para despertar sentimientos de indignación e instar a la gente a luchar por la venganza. Por ejemplo, Yoshinori Kobayashi en su manga Sensōron (1998) presenta una multitud de japoneses furiosos y deseosos de venganza leyendo las noticias del Motín de Tungchow de 1937 -una masacre de civiles y tropas japonesas por parte de militares chinos- para probar, en la lógica del autor, que la invasión japonesa de China estaba justificada. ${ }^{52}$

De la misma manera, el "pacifismo mesiánico”, que proponía que los eventos tenían un significado trascendente, presupone que la Segunda Guerra Mundial era necesaria para asegurar la paz de las próximas generaciones. Esto implica que la guerra fue un evento natural inevitable y no el resultado de decisiones humanas. Esta posición pasa por alto el hecho de que la mayor parte del precio de esa paz no fue pagada por los japoneses, sino por sus contrapartes asiáticas que, pese a todo, son convenientemente excluidas. Por último, si las guerras son inevitables, no tiene sentido aprender de la historia e intentar impedir que la gente abrace el camino del ultranacionalismo.

Ni siquiera el discurso "conciencia de perpetrador" está exento de implicaciones nacionalistas. El "remordimiento deuteronómico" parte de un fuerte sentido de identidad nacional que asume que todos los miembros pasados, presentes y futuros del colectivo japonés están intrínsecamente emparentados al punto que los actos infames cometidos por miembros pasados exigen responsabilidad a los miembros presentes. Enredados por esos sentimientos, no es sorprendente que los miembros pasados del grupo sean representados como héroes nobles o víctimas desesperadas por las que el miembro actual de la comunidad imaginada puede sentir admiración o empatía. Sin embargo, esta tendencia también es peligrosa en quienes pretenden que los japoneses asuman la "culpa", no solo por la guerra, sino por haber nacido japoneses. Esto no es únicamente injusto, sino también contraproducente: cuando se les acusa de crímenes que no cometieron, los neonacionalistas de las generaciones de la posguerra reaccionan negando que los crímenes hubiesen sucedido del todo o tratando

52 Kobayashi, Sensōron, 122. 
desesperadamente de relativizar sus crímenes al compararlos con atrocidades similares o peores cometidas por otros países.

Otra consecuencia en la "conciencia de perpetrador", incluso en la variante del "remordimiento reconciliador", es un uso indistinto de conceptos morales, legales y políticos como si tuviesen el mismo significado. Se usan términos como "culpa", "responsabilidad" o "reparación" sin hacer ninguna diferencia entre el grado de participación de los individuos en los hechos ni entre quienes vivían en aquella época y quienes nacieron después de acabada la guerra. Al respecto, algunos académicos han propuesto el concepto de "implicación", aceptando que las nuevas generaciones nunca deben ser acusadas de responsabilidad penal ni obligadas a aceptar la culpabilidad por hechos ocurridos antes de su nacimiento; y enfatizan que el tema debería ser tratado como "implicación política", buscando formas de mejorar las condiciones de vida de las víctimas en forma de reparaciones y donaciones, enseñando sobre la guerra en el sistema educativo para aprender de la historia y cultivando relaciones diplomáticas saludables con otros países. ${ }^{53}$

Una observación final es que quizá deba haber un término medio en la así llamada "conciencia de perpetrador". Por un lado, desarrollos recientes en la teoría democrática sostienen que la representación de un pasado criminal puede llegar a ser funcional porque abre la posibilidad de "un modo de identificación colectiva negativa”, eso quiere decir que las colectividades políticas "podrían encontrar más fácil establecer lo que no quieren hacer" y así promover la reconciliación con otros países y el diálogo en la esfera pública doméstica. ${ }^{54}$ Por otro lado, algunos autores han señalado con preocupación que la enorme exposición a la historia de la Alemania nazi ha producido un efecto opuesto en algunos jóvenes alemanes que tienden a "glorificar" en lugar de repudiar ese período. 55

53 El concepto de "implicación política” se desarrolla en Tessa Morris-Suziki, The Past Within Us. Media, Memory, History (New York: Verso, 2014).

54 Andreas Langenohl, "Memory in Post-Authoritarian Societies", en A Companion to Cultural Memory Studies, ed. por Astrid Erll y Ansgar Nünning (Berlin: Gruyter, 2010), 163-172.

55 Gregory Wegner, "The power of selective tradition: Buchenwald concentration camp and the Holocaust education", en Censoring History: Perspectives on 


\section{Conclusión}

Existen tantos recuerdos de un evento como personas lo vivieron. Sin embargo, con el paso del tiempo y el tránsito de las generaciones, la memoria colectiva se reduce y simplifica por medio de discursos que las personas reproducen, a veces inadvertidamente, en sus interacciones sociales. Los autores que han investigado la memoria de la Segunda Guerra Mundial en Japón han planteado tres grandes categorías discursivas que se han usado para explicar los orígenes del conflicto y otras tres categorías para las formas en las que las personas que vivieron ese periodo han sido representadas. El análisis de la literatura primaria admite que la categorización sobre los discursos acerca del origen de la Guerra es acertada, pero sugiere que el esquema tripartito de víctimas, perpetradores y héroes debe ser revisado pues incluye varias subcategorías con distintas implicaciones. La más notable es que, aunque se suele advertir que el neonacionalismo japonés se expresa en los discursos que justifican la guerra (justificación) y en las representaciones heroicas de los soldados (conciencia heroica), las subcategorías "pacifismo ingenuo", "pacifismo mesiánico" y "remordimiento deuteronómico" mencionadas en este artículo apuntan a una suerte de nacionalismos menos estudiados. Por ejemplo, la idea de que el simple deseo de alcanzar la paz es suficiente, divorciado de la enseñanza imparcial de la historia, así como la creencia de que los japoneses constituyen un pueblo elegido, tienen derroteros chovinistas, aunque se les incluya usualmente en la categoría de discursos pacifistas. Asimismo, la idea de que los japoneses actuales son responsables de los errores de sus antepasados, basándose en la idea de que forman parte de un colectivo homogéneo sin distinciones entre generaciones, tiene alcances nacionalistas en dos direcciones. Domésticamente, asume la existencia de una esencia que comparten los miembros pasados, presentes y futuros de la nación que les exige responsabilidad por hechos acontecidos antes de su nacimiento. Internacionalmente, miembros de otras naciones en el Este de Asia critican y desprecian a los japoneses actuales "en cuanto japoneses",

Nationalism and War in the Twentieth Century: Asia and the Pacific, ed. por Laura E. Hein y Mark Selden (New York: M. E. Sharpe, 2000), 226-257. 
creando así nuevos nacionalismos a partir de la construcción de un otro deshumanizado.

Finalmente, es necesario reconocer que las categorías provistas en este estudio, aunque basadas en una base de datos robusta, son perfectibles y no olvidan el factor de la subjetividad. Estudios posteriores podrían utilizar -y mejorar- algunas de estas categorías para analizar otras sociedades que también lidian con el resurgimiento del nacionalismo a partir de la reconstrucción parcializada de eventos pasados, pero partiendo del entendimiento de que no es posible encontrar síntesis definitivas en la siempre fluctuante memoria colectiva de los pueblos.

\section{Bibliografía}

Abercrombi, Nicholas et al. The Penguin Dictionary of Sociology 5th Edition. London: Penguin Books, 2006.

Asahi Shimbun. On'na-tachi no taiheiyōsensō 女たちの太平洋戦 争 [Las mujeres y la Guerra del Pacífico]. Tokio: Asahi Shimbun Editorial,1996.

Asahi Shimbun. Sensō chi to namida de tsudzutta shōgen 戦争 血と涙で 綴つた証言 [La Guerra: Testimonios escritos con sangre y lágrimas]. Tokio: Asahi Shimbun Editorial, 1987.

Asociación de la Ciudad de Hiroshima. Genbaku taiken-ki 原爆体験記 [Archivo de experiencias de la bomba atómica]. Hiroshima: Asahi Editorial, 1975.

Asociación de veteranos de la Armada Imperial de Japón. Nihon rikukaigun no sōkessan zasshi 日本陸海軍の総決算 雑誌. Tokio: Bungeishunjū, 1955.

Bar-Tal, Daniel. Intractable Conflicts: Socio-Psychological Foundations and Dynamics. Cambridge: Cambridge University Press, 2013.

Dazai, Osamu. Shayo斜陽 [El ocaso]. Tokio: Iwanami, 1947/1988.

Dear, Ian y Michael R. D. Foot. The Oxford Companion to World War II. Oxford: Oxford University Press, 1995. 
De Vargas, Ferran. Izquierda y Revolución. Una historia politica del Japón de posguerra (1945-1972). Barcelona: Editorial Bellaterra, 2020.

Dower, John W. Embracing Defeat: Japan in the Wake of World War II. New York: The New Press, 1999.

Dower, John W. Ways of Forgetting, Ways of Remembering Japan in the Modern World. New York: The New Press, 2012.

Eguchi, Keichi. Jū go-nen sensō shoshi 十五年戦争小史. Tokio: Aoki Shoten, 1991.

Eguchi, Keichi. Nibon fashizumu no keisei 日本ファシズムの形成. Tokio: Nihonhyōronsha, 1978.

Fellers, Bonner F. "Basic military plan for psychological warfare against Japan” (Manila, Report No. 11-a (15), USSBS Index Section 6, May 1945).

Fujioka, Nobukatsu. Ojoku no kin gendai-shi 污辱の近現代史一いま、 克服のとき. Tokio: Tokuma Shoten, 1996.

Fukuoka, Kazuya. "Memory and Others. Japan's mnemoic turn in the 1990s". En Routledge Handbook of Memory and Reconciliation in East Asia, editado por Mikyoung Kim. Abingdon: Routledge, 2015.

Gerow, Aaron. "Fantasies of war and nation in recent Japanese cinema". Japan Focus IV, no. 2 (2006).

Gluck, Carol. "The idea of Showa", Daedalus 119, no. 3, (1990): 1-26.

Gluck, Carol. "The Past in the Present". En Postwar Japan as History. Editado por Andrew Gordon. California: University of California Press, 1993.

Hashimoto, Akiko. The Long Defeat: Cultural Trauma, Memory, and Identity in Japan. New York: Oxford University Press, 2015.

Hattori, Ryuji. Understanding History in Asia What Diplomatic Documents Reveal. Tokio: Japan Publishing Industry Foundation for Culture, 2019.

Hattori,Shiso. Hattorishisōzenshūnihon teikokushugiron 服部之総全集 〈19〉日本帝国主義論. Tokio: Fukumura Press, 1974. 
Hattori, Takushiro. Daitōasensōzenshi $i$ 東亜戦争全史. Tokio: Intelfin Inc., 1953.

Hayashi, Fusao. Daitōasensō kōtei-ron 大東亜戦争肯定論. Tokio: Chūōkōronshinsha, 1963/2014.

Hein, Laura E. y Mark Selden. Censoring History: Perspectives on Nationalism and War in the Twentieth Century: Asia and the Pacific. New York: M. E. Sharpe, 2000.

Hodder, Ian. "The Interpretation of Documents and Material Culture". En Handbook of Qualitative Research, editado por Norman K. Denzin e Yvonna S. Lincolnn. California: Sage, 1994.

Honda, Katsuichi. Chügoku no tabi 中国の旅. Tokio: Asahi Shimbun editorial, 1972.

Ienaga, Saburō. Taibeiyōsensō 太平洋戦争. Tokio: Nihonrekishisōsho, 1968.

Inoue, Kiyoshi. Nibon teikoku shugi no keisei 日本帝国主義の形成. Tokio: Iwanami Shoten, 1968/2001.

Ito, Masanori. Rengō kantai no eikō連合艦隊の栄光 [La gloria de la flota combinada]. Tokio: Kojinsha, 1962/1996.

Ito, Masanori. Rengō kantai no saigo: Taibeibiromi senshi 連合艦隊の 最後: 太平洋海戦史 [El final de la Armada Imperial de Japón: La Guerra del Pacífico]. Tokio: Kojinsha, 1956/2004.

Kawakami, Hajime. Jijoden自叙伝 [Autobiografía]. Tokio: Iwanami, 1946/1976.

Kim, Mikyoung (ed.). Routledge Handbook of Memory and Reconciliation in East Asia. Abingdon: Routledge, 2015.

Kobayashi, Yoshinori. Sensōron 戦争論. Tokio: Gentosha, 1998.

Kurihara, Sadako. When We Say "Hiroshima": Selected Poems. Michigan: University of Michigan Center for Japanese Studies Press, 1999.

Kuroda, Hidetoshi. Mono ienu jidai もの言えぬ時代. Tokio: Tosho, 1986. 
Langenohl, Andreas. "Memory in Post-Authoritarian Societies". En $A$ Companion to Cultural Memory Studies. Editado por Astrid Erll y Ansgar Nünning. Berlin: Gruyter, 2010.

Maruyama, Masao. Nihon seiji shisō-shi kenkyū 日本政治思想史研究 [Estudios sobre la historia del pensamiento político japonés]. Tokio: Editorial de la Universidad de Tokio, 1952).

Ministerio de Educación de Japón. Kuni no Ayumiくにのあゆみ. Tokio: Tōkyōshoseki, 1946.

Miki, Kiyoshi. Tetsugaku nōto哲学ノート [Notas filosóficas].. Tokio: Chūkōbunko, 1941/2010.

Morimoto, Seichi. Akuma no hōshoku: Nihon saikin-sen butai no kyōfu no jitsuzo 悪魔の飽食一日本細菌戦部隊の恐怖の実像 [La gula del diablo: El verdadero horror de la unidad de guerra bacteriológica japonesa]. Tokio: Kadokawa, 1981.

Morris-Suziki, Tessa. The Past Within Us. Media, Memory, History. New York: Verso, 2014.

Morioka, Kiyomi. Wakaki tokkōtai-in to taibeiyōsensō: sono shuki to gunzō 若き特攻隊員と太平洋戦争 その手記と群像 [Jóvenes de las Unidades Especiales de Ataque y la Guerra del Pacífico: Memoria e imagen]. Tokio: Yoshikawa Kōbunkan, 2011.

Naka, Hisao. Sengonibon no naka no 'sensōo 戦後日本のなかの「戦争」. Tokio: Sekaishisōsha, 2004.

Natsume, Fusanosuke. Manga to 'sensōo マンガと「戦争」. Tokio: Kodansha, 1997.

Oficina de Estadística de Japón. Población por Grupo de Edad e Índices de Estructura de Edad (1920- presente). URL: http://www.stat. go.jp/english/index.html

Oguma, Eiji. 'Nihonjin' no kyōkai: Okinawa Ainu Taiwan Chōsen shokuminchi shibai kara fukki undō made「日本人」の境界一沖 縄・アイヌ・台湾・朝鮮 植民地支配から復帰運動まで. Tokio: Shinyosha, 1998. 
Olick, Jeffrey K. "From Collective Memory to the Sociology of Mnemonic Practices and Products". En A Companion to Cultural Memory Studies, editado por Astrid Erll y Ansgar Nünning. Berlin/ New York: Gruyter, 2010.

Orr, Joseph J. The victim as hero ideologies of peace and national identity in postwar Japan. Honolulu: University of Hawai'i Press, 2017.

O'Sullivan, Tim et al. Key Concepts in Communication and Cultural Studies. London: Routledge, 1994.

Ōuchi, Tsutomu. Nibon'norekishi, 24: fashizumu e no michi 日本の歴史 〈24〉ファシズムへの道. Tokio: Chūkō bunko, 2006.

Ozaki, Hotsumi. Aijō wa furu hoshi nogotoku 愛情はふる星のごとく[E] amor es como una lluvia de estrellas] Tokio: Iwanami, 1946/2003.

Radich, Michael. A Student's Guide Writing in East Asian Studies. Cambridge: Harvard University Press, 2007.

Riessman, Catherine K. Narrative analysis. California: SAGE Publishings, 1993.

Ruiz, Jorge. "Sociological Discourse Analysis: Methods and Logic". Forum Qualitative Sozialforschung X, no. 2 (2009), https://doi. org/10.17169/fqs-10.2.1298.

Sakaguchi, Ango. Daraku-ron 堕落論 [Teoría de la decadencia]. Tokio: Shinchō bunko, 1946/2000.

Sasagawa, Ryochi. Sugamo no byōjōo-senpan gokuchū biwa 巣鴨の表情戦犯獄中秘話. Tokio: Bunkajin shobō, 1949.

Stickland, Leonie R. The Boundaries of "The Japanese": Okinawa 18181972 Inclusion and Exclusion. Tokio: Trans Pacific Press, 2014.

Takeyama, Michio. Biruma no tategotoビルマの竪琴 [El arpa birmana]. Tokio: Shinchō bunko, 1946/1959

Nagai, Takashi. Nagasaki no Kane 長崎の鐘 [Las campanas de Nagasaki]. Tokio: San Paulo Editorial, 1949.

Takahashi, Yoshinori. "1960 nendai shōnen shūkanshi ni okeru 'sensō” shōnen magajin’ no jirei” 一九六○年代少年週刊誌における「 戦争」「少年マガジン」の事例. En Sengonibon no naka no 'sensō', 
editado por Hisao Naka. Tokio: Sekai shisō-sha, 2004.

Tamura, Taijiro. Nikutai no mon 肉体の門 [Las puertas de la carne]. Tokio: Shinchō bunko, 1947/1968. The Institute for the Study of Human Rights (ISHR). Columbia University, Section of Political Apologies. URL: http://www.humanrightscolumbia.org/ahda/ political-apologies

Toland, John. The Rising Sun: The Decline and Fall of the Japanese Empire, 1936-1945. New York: Random House, 1970.

Tsuji, Masanobu.Jū go tai ichi: Biruma no shitō十五対一 -ビルマの死 闘. Tokio: Kantōsha, 1950.

Tsuji, Masanobu. Shingapōru - unmei no tenkiシンガポール -運命の転 機. Tokio: Tozainanbokusha, 1952.

Tsutsui, Kiyoteru. “The Trajectory of Perpetrators' Trauma: Mnemonic Politics around Asia-Pacific War in Japan”. Social Forces 87, no. 3 (2009): 1389-1422.

Victor, George. Hitler: The Pathology of Evil. Nebraska: Potomac's Paperback Classics, 1999.

Vogel, Ezra F. China and Japan Facing History. Cambridge: Harvard University Press, 2019.

Vollhardt, Johanna Ray. "The Role of Inclusive and Exclusive Victim Consciousness in Predicting Intergroup Attitudes: Findings from Rwanda, Burundi, and DRC”. Political Psychology XXXVI, no. 5 (2015): 489-506.

Watanabe, Kiyoshi. Kudakareta kami aru fukuin-hei no shuki 砕かれた 神 ある復員兵の手記. Tokio: Iwanami, 1949/2004.

Wegner, Gregory. "The power of selective tradition: Buchenwald concentration camp and the Holocaust education". En Censoring History: Perspectives on Nationalism and War in the Twentieth Century: Asia and the Pacific, editado por Laura E. Hein y Mark Selden. New York: M. E. Sharpe, 2000. 
Esteban Córdoba | Prácticas discursivas

Yamazaki, Jane. Japanese Apologies for World War II. London: Routledge, 2006.

Yoshida, Yutaka. Nihonjin no sensōkan sengōshi no naka no hen'yō日本人 の戦争観 戦後史のなかの変容. Tokio: Iwanami Gendai Bunkō, 2005.

Young, Louise. Japan's Total Empire: Manchuria and the Culture of Wartime Imperialism. California: University of California Press, 1998. 


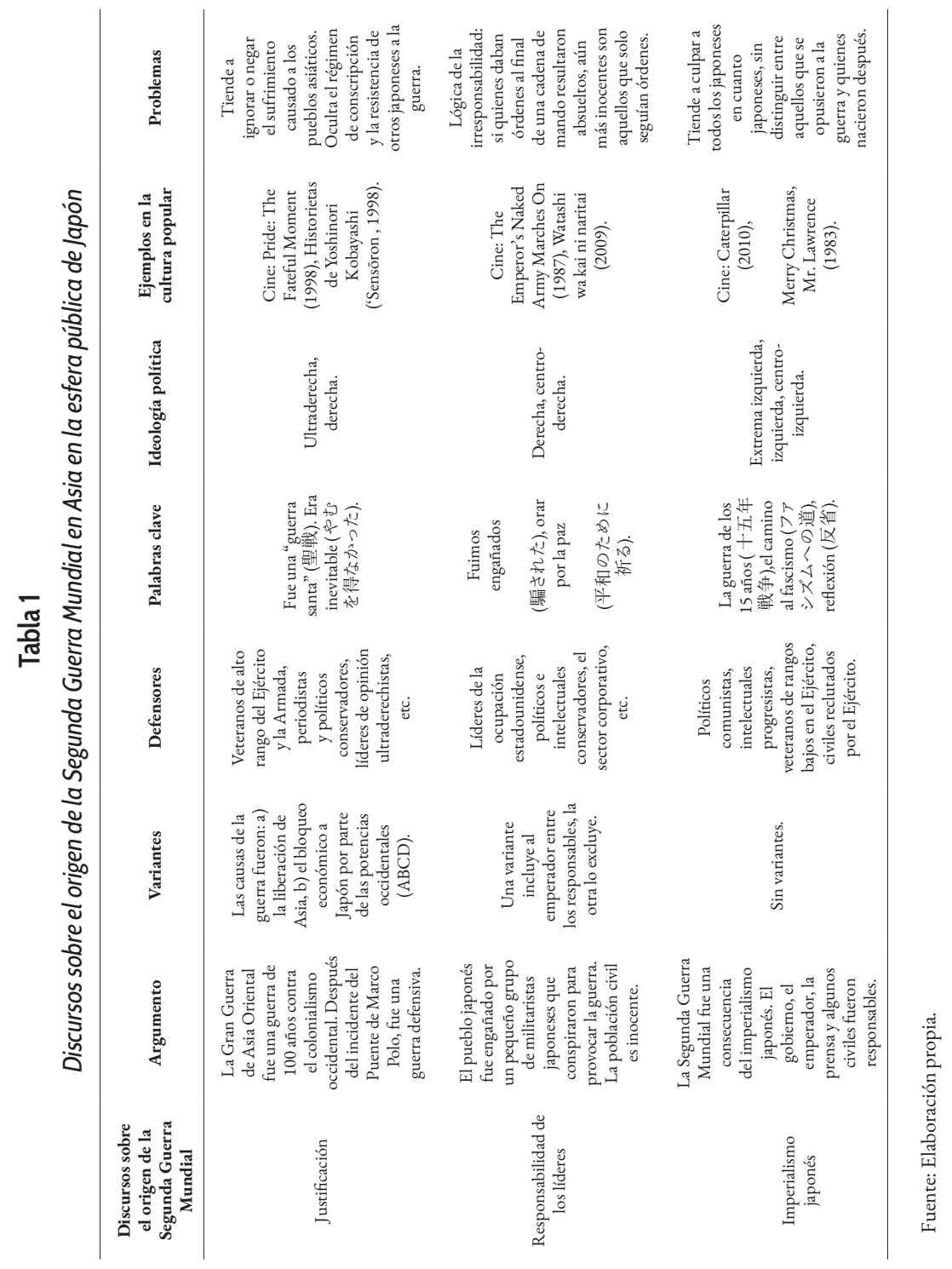


Esteban Córdoba | Prácticas discursivas

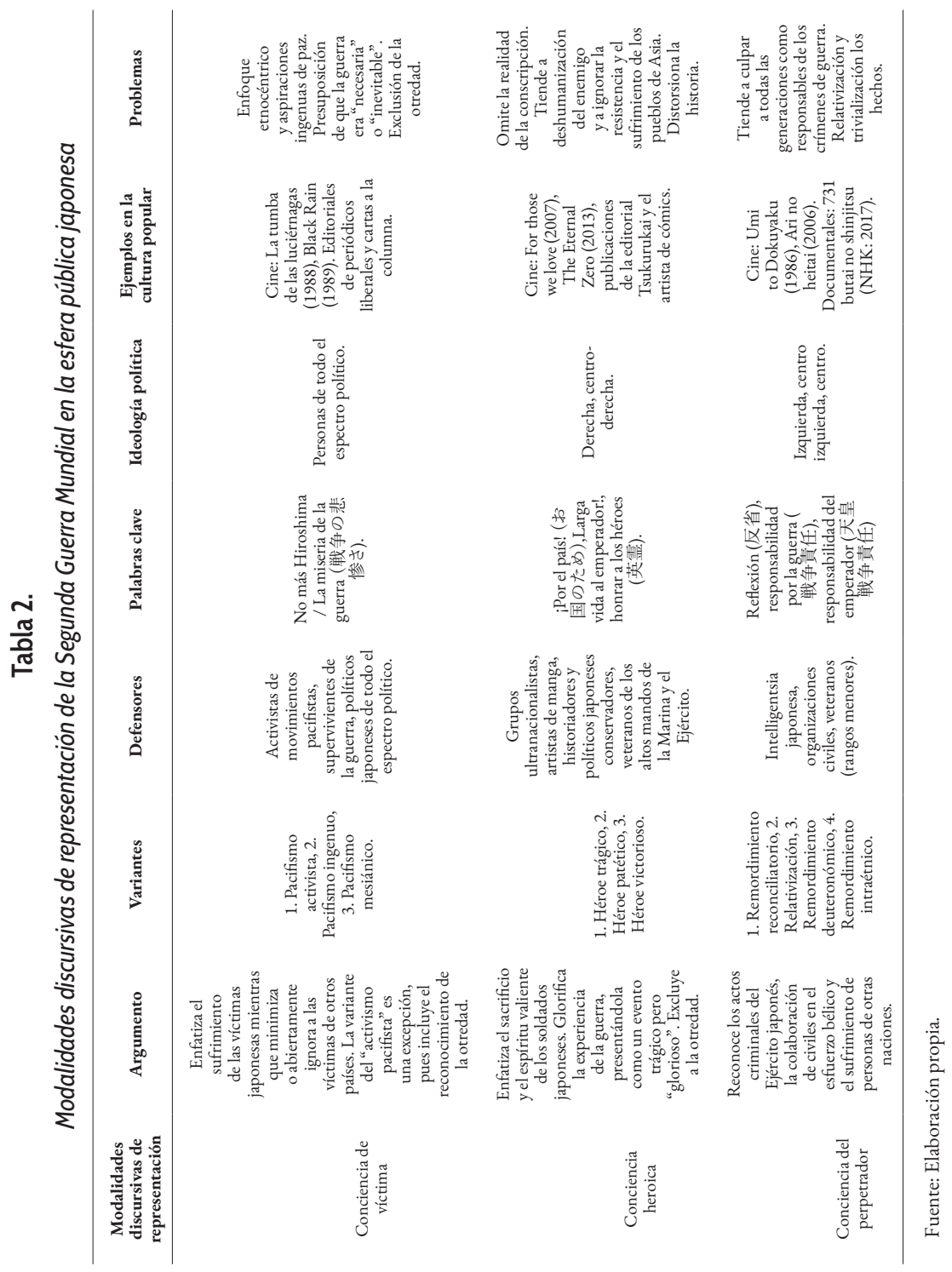

